\title{
Re-Clustering Approach using WCA in DSR and OLSR Routing Protocols in MANET
}

\author{
Harshit Prakash Patidar and Neetu Sharma
}

\begin{abstract}
Based on the characteristic of the Mobile Adhoc Network (MANET), this paper recommends a secure protocol of MANET by the uses of the Weighted Clustering Algorithm. All the nodes within the networks are flustered into several clusters in the protocols. Here, we analyze how to compute the genuine value between the nodes according to their communication performances. We can justify where the connection between the two nodes is trustable or not by the genuine value. According to the number of the trustable connections, we can choose the clusterhead within the cluster and the nodes which have trustable connection with clusterhead will be the core nodes. The clusterhead and core nodes can work together to be the service group for the cluster; the service group is in charge of giving service for various requests from cluster members. Each node will share a secret information which will be a part of a secret key for itself and come into being the authentication factor in the proceeding of investigation about the update requirement in the next circle. The secret share can also be authenticated by the node itself. Once a node has been confirmed as a malicious node, clusterhead will broadcast the information to all the cluster members and refuse to provide update services for that particular malicious node. The protocol has absolute forward and backward privacy. The keys of nodes and cluster are generated after conversation among the service group members, man-in-the-middle attack can be resisted by this way. At the same time, the cluster can complete the periodic update, the clusterhead will be re-selected, the service group will be reformed, consequently, the key of cluster and nodes will update as well.
\end{abstract}

Above all, what we have done in this paper will make assure the MANET will run in a safe mode and more efficient way.

Keywords--- Mobile Ad-hoc Network, Clustering, Cluster head, Key-server

\section{INTRODUCTION}

$\mathrm{C}$ COLLECTION of mobile nodes which are infrastructure less and automatic-configuring are called Mobile Ad-hoc Network. Change in position and topology without any centralization control in the network is the basic functionality of mobile nodes. Every intermediate node act like router and server, responsible for analysis of the network and broadcasting data. A group of mobile nodes is called ad-hoc

Harshit Prakash Patidar, Department of Computer Science, Govt. Engineering College, Ajmer, Rajasthan.E-mail:harshitprakash@gmail.com

Neetu Sharma, Department of Computer Science, Govt. Engineering College, Ajmer, Rajasthan. E-mail:neetucom10@gmail.com

DOI: 10.9756/ BIJNTA.8130 network which is predefined infrastructure. Mobile Ad-hoc Network has dynamic functionality so node can be used for some time in the network. In Manet, node is also transferred within the network or from one ad-hoc network to another radhoc network. In recent times, only two different types of wireless Mobile Ad-hoc Network are available- Base station and Mobile Ad-hoc Network. All dynamic locations are controlled by mobility model. This mobile modelchecks the dynamic performance and uses a specific parameter of various different routing protocols. [1]

\section{OVERVIEW OF OLSR AND DSR ROUTING PROTOCOLS}

According to the situation and when routes are discovered then routing protocols are divided into two categories but both find the shortest path from the source to the destination. Tabledriven routing protocols are proactive routing protocols. They always maintain routing information up-to-date by sending control messages periodically between the hosts which update their own routing tables. The updates are propagated throughout the network when changes are made in the structure. Link-state routing algorithms are used by proactive routing protocols which repeatedly flood the link information about its neighbours. Other routing protocols are on-demand routing protocols, in other sentences, they are reactive in behaviour, ones which create routes when they are needed by the source host and these routes are maintained while they are needed. Distance vector routing algorithms are used by this kind of protocol, they have vectors holding information about the cost and the path from the source to the destination. When vectors of information are exchanged with nodes, each host modifies its own routing information when required. The adhoc routing protocols are usually classified as a completely proactive or a completely reactive protocol but there are also hybrid protocols. This is only an apprehension of flat routing protocols but there are also hierarchical and graphic position assisted routing protocols. [1]

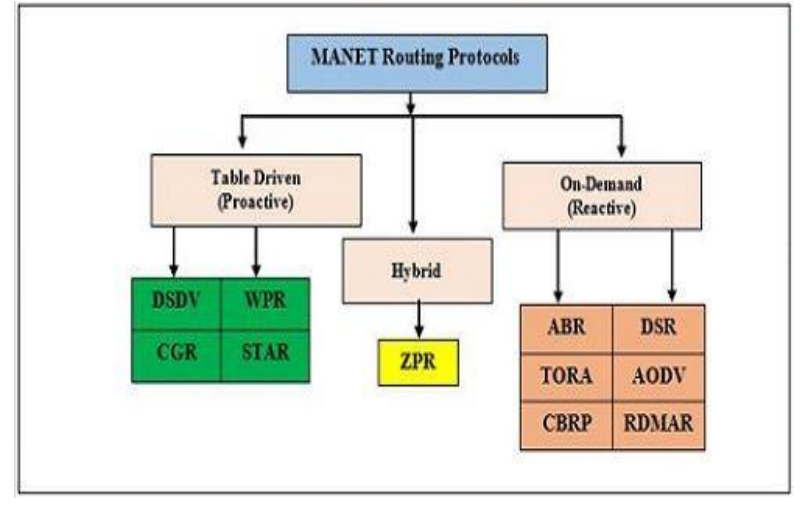

Figure 1: Classification of Routing Protocols 


\section{A. Proactive (Table-driven) Routing Protocol}

Each node in the network has an own routing table for the broadcast of the data packets and want to establish connection to other nodes. These nodes record for all the presented destinations and number of hops required to arrive at each destination in the routing table. The routing entry is attached with a sequence number which is generated by the destination node. To maintain the stability, each location broadcasts and modifies its routing table from time to time. How many hops are needed to reach that particular hope and which locations are accessible is the result of the broadcasting of packets between hopes. Each hope that broadcasts data will contain its new sequence number and for each new route, hope contains the following information:

- How many hops are required to arrive that specific destination node.

- Generation of new sequence number marked by the destination.

- The destination address.

The proactive routing protocols are appropriate for minimum number of nodes in the networks as they need to update node entries for each and every node in the routing table of every node. It results in more Routing overhead problem in the network. There is an additional bandwidth consumption in the routing table. [2]

- Example of Proactive Routing Protocol is Optimal Link State Routing (OLSR).

\section{Optimal Link State Routing Protocol (OLSR)}

Proactive Routing Protocol interchanges routing information with other nodes in the network. The main technique used in OLSR is Multi Point Relays (MPRs). It is optimized to decrease the number of control packets required for the data transmission using the MPRs. To forward data traffic, a node selects its one hop symmetric neighbours termed as a MPR set that covers all nodes that are two hops away. In OLSR protocol, only nodes selected as MPRs are responsible for forwarding control traffic. The selected MPRs broadcast messages during the flooding process. Disobediently to the classical link state algorithm where all the nodes broadcast messages. Thus, mobile nodes can reduce battery consumption in Optimal Link State Routing associated with other link state algorithms. [2]

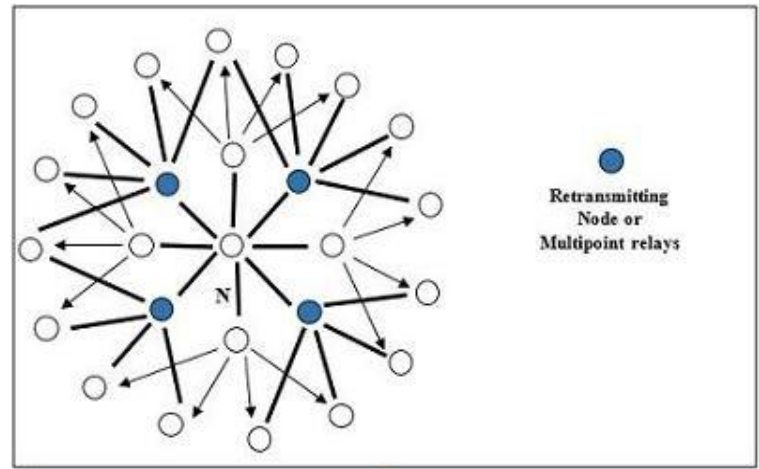

Figure 2: OLSR Routing Protocol

\section{B. Reactive (On-demand) Routing Protocol}

Reactive Routing Protocol has minor overhead because routes are determined on-demand. It services flooding (global search) concept. Continuously updating of the route tables with the latest route topology is not required in on-demand concept.

Reactive Routing Protocol searches for the route in an ondemand style and set the link in order to send out and accept the packet from a source node to the destination node. Route discovery process is used in on-demand routing by flooding the route request (RREQ) packets throughout the network. [3]

- Examples of reactive routing protocols are the Dynamic Source Routing (DSR), Ad-hoc On-demand Distance Vector (AODV).

\section{Dynamic Source Routing Protocol(DSR)}

Source routing technique is used by Dynamic Source Routing protocol. When packets are flooded by a source node, the sender node picks complete hop-by-hop route to the receiver node. These route lists are picks in a route pick. The source route is carried by the data packets in the packet header. Route Discovery process is used by DSR to send the data packets from sender node to receiver node; for which it does not already know the route, it uses a route discovery process to dynamically define such a route. In Route discovery, DSR works by flooding the data packets in the network with route request (RREQ) packets. RREQ packets are received by every neighbour nodes and continue this flooding process by retransmissions of RREQ packets unless it gets to its destination or its route cache contains a route to destination. Such a node replies to the RREQ with a route reply (RREP) packet that is routed back to the real source node. Source routing uses RREQ and RREP packets. The RREQ builds up the path traversed across the network. The RREP routes itself back to the source by negotiating this path toward the back. The source caches backward route by RREP packets for future use. If any connection on a source route is exhausted, a route error (RERR) packet is informed to the source node. [3]

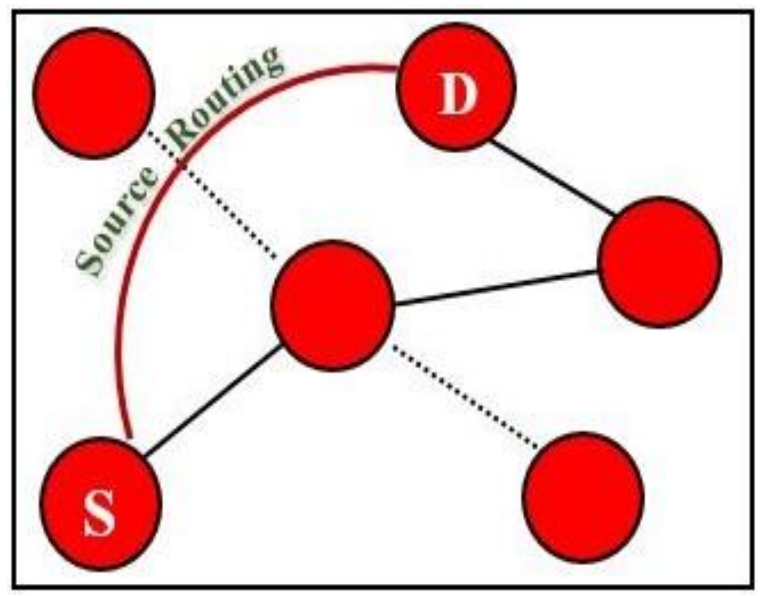

Figure 3: DSR Routing Protocol 


\section{DESCRIPTION OF MOBILITY MODEL}

In mobility management, the Random Waypoint Mobility Model is a random model for the movement of mobile users explaining how their location, velocity and acceleration changes over the time. Mobility models are used for simulation purposes when fresh network protocols are estimated. The random waypoint mobility model was first suggested by Johnson and Maltz. It is one of the most popular mobility models to evaluate Mobile Ad-hoc Network (MANET) routing protocols because of its simplicity and wide availability.

In random-based mobility simulation models, the mobile nodes move dynamically and independently without any limitations. To be more specific, the destination, speed and way are all chosen dynamically and independently of the other nodes. This type of model has been used in many simulation tasks.

The Random Walk Mobility Model and the Random Direction Mobility Model are two different kinds of variants of the Random Waypoint Mobility Model. [4]

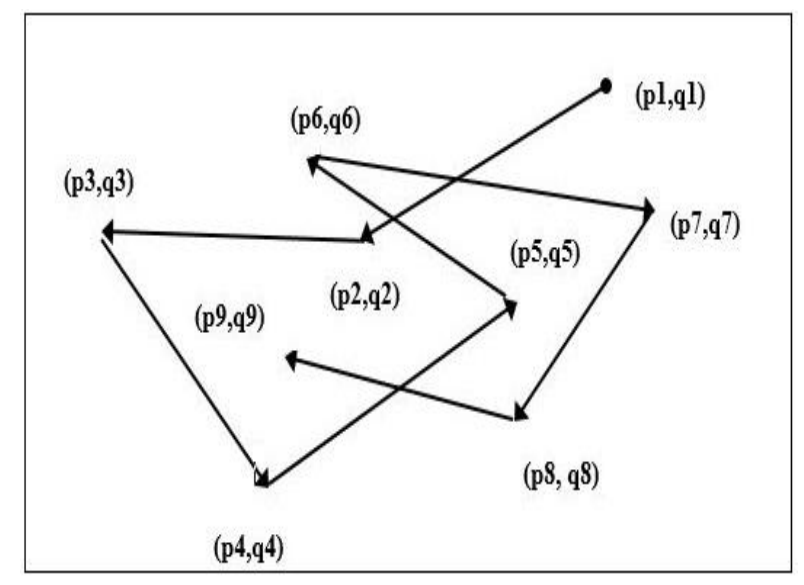

Figure 4: Random Waypoint Mobility Model

\section{ENERGY CONSUMPTION MODEL}

We have calculated the energy consumption for data transmission and receiving as proposed by Dongkyun Kim (Dongkyun Kim. Et al. 2002) and for key generation proposed by Potlapally Nachiketh (Nachiketh R. et al. 2003).

The energy consumption needed to transmit a packet $p$ then the energy $E(p)=i * v * t_{p}$ Joules where $i$ is new value, $v$ is the voltage and $t_{\mathrm{p}}$ is the time occupied to transmit the packet $\mathrm{p}$. Energy consumption for the key setup phase using AES of 128-bit key is $7.83 \mathrm{uJ} / \mathrm{key}$. We use symmetric key of AES of 128-bit length for simulation.[5]

\section{OUR APPROACH}

Three experiments have been discussed above and each experiment is directed to optimize selection of clusterheads as each deals with one subset of parameters that imposes limitations on the system. Due to resource constraints, clusterhead might not handle the nodes even if the adjacent nodes lie within the transmission range. Therefore, to handle the load capacity of clusterhead an upper bound is enforced. In the simple words, covering the area least number of clusterheads will impose more weight on clusterheads but at the same time, more clusterheads imply costlier system. This might eventually lead to better throughput but it will also lead to high latency as the data packets now need to go through multiple hops. Thus, it is still a big problem to choose an optimal number of clusterheads as increasing them would lead to high throughput which will lead to high latency which is not preferred. Therefore, we suggest using combined weighted metrics that take into consideration various parameters like ideal node degree, mobility, transmission power and the battery power of the nodes. [6] [7]

We should have a fully dispersed system where all nodes share same responsibility and performance as clusterheads. However, more number of clusterheads means more number of hops from source to destination as the packet currently needs to go through the large number of clusterheads. This result leads to more power consumption, higher latency and more information processing per node. For more resource utilization, we need to have minimum number of clusterheads that shelters the entire geographical area over which the nodes are dispersed. The complete area can be divided into two regions; the size of which can be defined by nodes transmission range. [6] [7]

\section{Clusterhead Selection Technique}

Step 1: Find the neighbours of each node v (i.e. nodes within its broadcast range). This gives the degree, $d_{v}$, of this node. $\mathrm{H}$ is number of nodes, a clusterhead can handle.

Step 2: Calculate the degree-difference, $D_{v}=\left|d_{v}-H\right|$, for every node $\mathrm{v}$.

Step 3: For every node, compute the sum of the distances, $S_{v}$, with all its neighbours.

Step 4: Calculate the running average speed for every node $\mathrm{v}$. This provides the mobility of the nodev and is denoted by $\mathrm{M}_{\mathrm{v}}$.

Step 5: Calculate the consumed battery power, $\mathrm{T}_{\mathrm{v}}$. Since we assume that consumption of battery power is more for a clusterhead than for an ordinary node.

Step 6: Calculate a combined weight $I_{v}=c_{1} * D_{v}+c_{2} * S_{v}$ $+c_{3} * M_{v}+c_{4} * T_{v}$, for each node $v$.

The coefficients $c_{1}, c_{2}, c_{3}$ and $c_{4}$ are the weighting factors for the corresponding system parameters.

Step 7: Calculate the average weights of all nodes, AI, and also compute the average Rekey Probabilities of all nodes, ARP.

Step 8: Now check for each node $\mathrm{v}$,

If (weight $\mathrm{I}_{\mathrm{v}}<\mathrm{AI}$ and corresponding Rekey Probability, $\left.\mathrm{RP}_{\mathrm{v}}<\mathrm{ARP}\right)$

Then Calculate the new weight $\mathrm{NI}_{\mathrm{v}}=\mathrm{I}_{\mathrm{v}} * 0.001+\mathrm{RP}_{\mathrm{v}}$.

Step 9: Choose the node with minimum $\mathrm{NI}_{\mathrm{v}}$ to be the clusterhead. (Key-server) 
By using the improved WCA algorithm, primarily we choose the best node as clusterhead from the existing nodes to escape Re-clustering. The following key features are considered in this Weighted Clustering Algorithm:

- The clusterhead selection method is aperiodic and is invoked as hardly as possible. It reduces system updates and reduces computational and communicational costs.

- To confirm efficient MAC functioning, each clusterhead can ideally support a pre-defined system threshold node. By optimizing or limiting the number of nodes in each cluster, the systems high throughput can be achieved.

- The battery power can be skillfully used within certain transmission range. If a node works as a clusterhead rather than an ordinary node, consumption of the battery power is additional. [8]

\section{SimULATION RESUlT AND ANALYSIS}

We have simulated Re-clustering in Mobile Ad-hoc Network. Simulation is implemented in $\mathrm{C}++$ language. We performed experiments on groups of 128, 256, 512, 768 and 1024 nodes. For each experiment, we have generated the joining/leaving of nodes randomly, in addition, some members may leave because of power exhaustion and some members may join/leave based on connection failure or availability. For each join/leave operation, we have recorded the numbers of Rekeys generated, energy consumption for key generation and energy consumption for data transmission.

In Re-clustering approach, we have categorized three categories namely static, semi-dynamic and dynamic based on the number of leaves and Rekey Probabilities. But in MANET, we added some extra parameters to classify these categories. The additional parameters are pause time, node mobility and updating interval time. The additional parameters are listed in Table 1. In simulation, for every updating interval time, we have updated the node positions and routing tables.

\section{Simulation Parameters}

Table 1: Simulation Parameters

\begin{tabular}{|l|l|l|l|}
\hline $\begin{array}{l}\text { Simulation } \\
\text { Parameters }\end{array}$ & Static & Semi-Dynamic & Dynamic \\
\hline Mobility & $0-5 \mathrm{~m} / \mathrm{s}$ & $0-10 \mathrm{~m} / \mathrm{s}$ & $0-20 \mathrm{~m} / \mathrm{s}$ \\
\hline Packet Size & 256 bytes & 256 bytes & 256 bytes \\
\hline Mobility Model & $\begin{array}{l}\text { Random } \\
\text { Waypoint }\end{array}$ & $\begin{array}{l}\text { Random } \\
\text { Waypoint }\end{array}$ & $\begin{array}{l}\text { Random } \\
\text { Waypoint }\end{array}$ \\
\hline Pause Time & $0-10 \mathrm{~s}$ & $0-5 \mathrm{~s}$ & $0 \mathrm{~s}$ \\
\hline $\begin{array}{l}\text { Updating Interval } \\
\text { Time }\end{array}$ & $10 \mathrm{~s}$ & $5 \mathrm{~s}$ & $1 \mathrm{~s}$ \\
\hline $\begin{array}{l}\text { No. of Leaves } \\
\text { Area (in sq. m) }\end{array}$ & $\begin{array}{l}1 / 4 \text { of Group } \\
\text { Size }\end{array}$ & $\begin{array}{l}1 / 2 \text { of Group } \\
\text { Size }\end{array}$ & $\begin{array}{l}3 / 4 \text { of Group } \\
\text { Size }\end{array}$ \\
\hline Energy & $800 x 800$ & $800 x 800$ & $800 x 800$ \\
\hline
\end{tabular}

Simulation Results

In simulation results, we present the Rekey Cost and energy consumption values for 0 to 5 times Re-clustering in Static, Semi-Dynamic and Dynamic scenarios. As the number of Re-clustering increases, the Rekey Cost and other energy consumptions also increases for each group size of 128, 256 ,512, 768 and 1024 nodes.

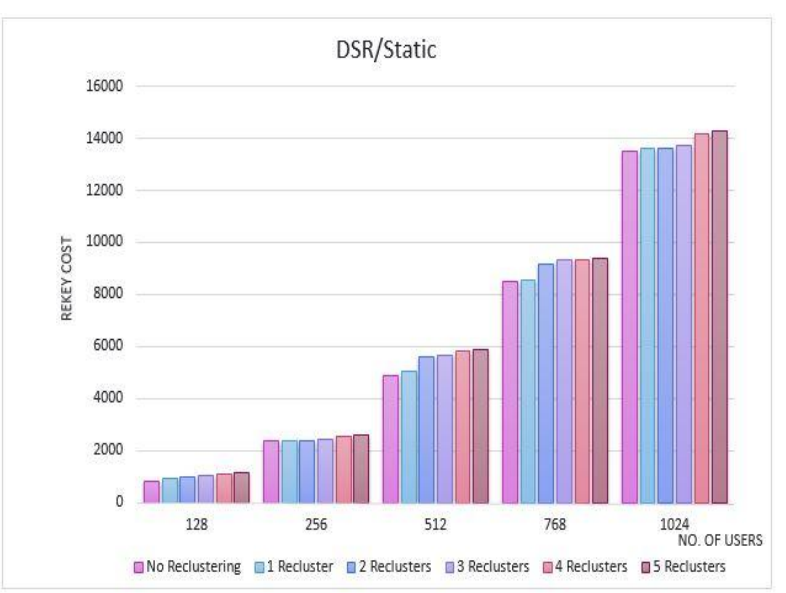

Figure 5: Group Size versus Rekey Cost (Static Scenario) for 0 to 5 times Re-clustering

Figure 5 displays Rekey Cost in the network in case of Static category for 0 to 5 times Re-clustering in Dynamic Source Routing Protocol. Rekey Cost in the Static category is less as compared to the Semi-Dynamic category and Dynamic category. Here, it is observed that if the number of Reclustering increases, the Rekey Cost also increases.

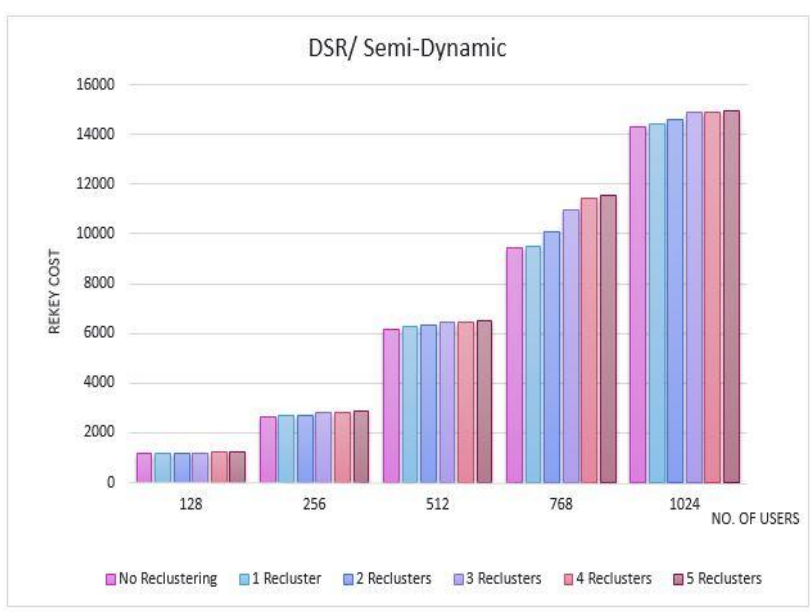

Figure 6: Group Size versus Rekey Cost (Semi-Dynamic Scenario) for 0 to 5 times Re-clustering

Figure 6 displays Rekey Cost in the network in case of Semi-Dynamic category for 0 to 5 times Re-clustering in Dynamic Source Routing Protocol. Rekey Cost in the SemiDynamic category is less as compared to the Dynamic category. Here, it is observed that if the number of Reclustering increases, the Rekey Cost also increases. 


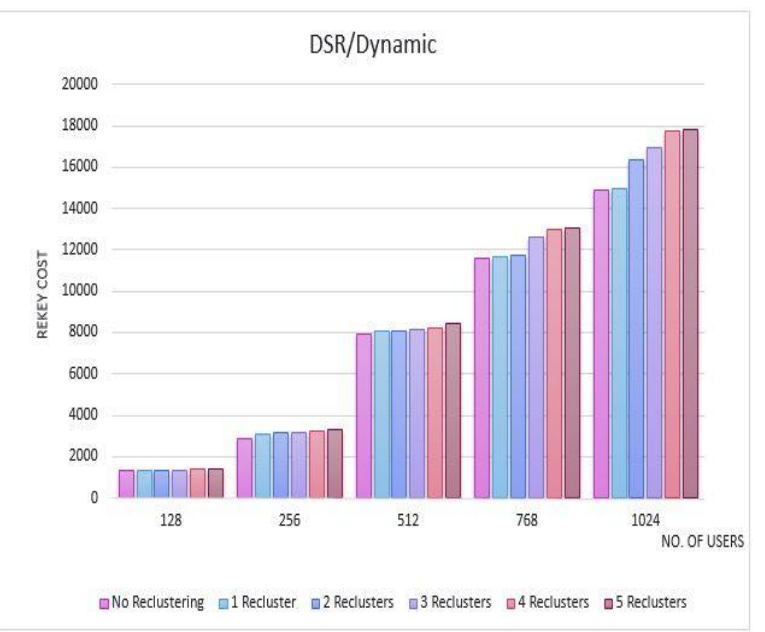

Figure 7: Group Size versus Rekey Cost (Dynamic Scenario) for 0 to 5 times Re-clustering

Figure 7 displays Rekey Cost in the network in case of Dynamic category for 0 to 5 times Re-clustering in Dynamic Source Routing Protocol. Rekey Cost in the Dynamic category is more as compared to the Static category and Semi-Dynamic category. Here, it is observed that if the number of Reclustering increases, the Rekey Cost also increases.

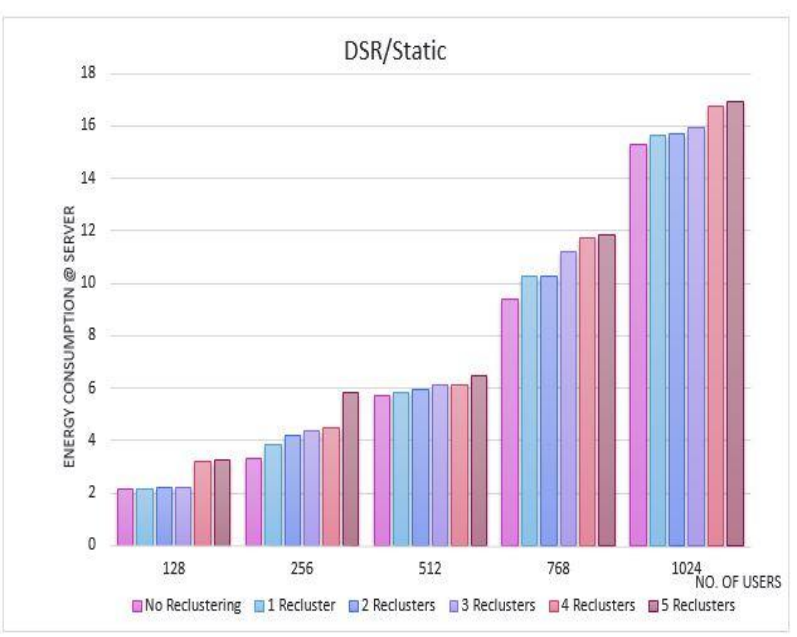

Figure 8: Group Size versus Energy Consumption at Server

(Static scenario) for 0 to 5 times Re-clustering

Figure 8 displays Energy Consumption at Server in the network in case of Static category for 0 to 5 times Reclustering in Dynamic Source Routing Protocol. Energy Consumption at Server in the Static category is less as compared to the Semi-Dynamic category and Dynamic category.

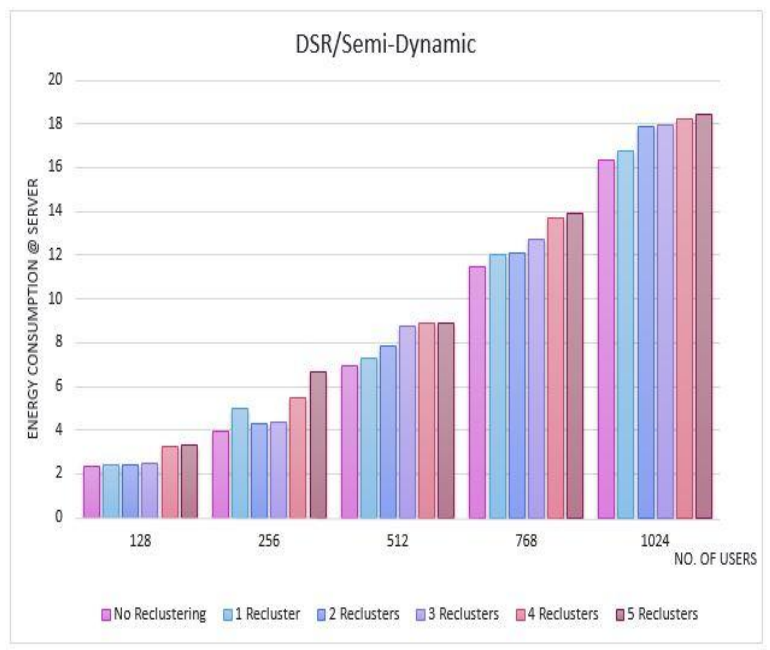

Figure 9: Group Size versus Energy Consumption at Server (Semi-Dynamic scenario) for 0 to 5 times Re-clustering

Figure 9 displays Energy Consumption at Server in the network in case of Semi-Dynamic category for 0 to 5 times Re-clustering in Dynamic Source Routing Protocol. Energy Consumption at Server in the Semi-Dynamic category is less as compared to the Dynamic category.

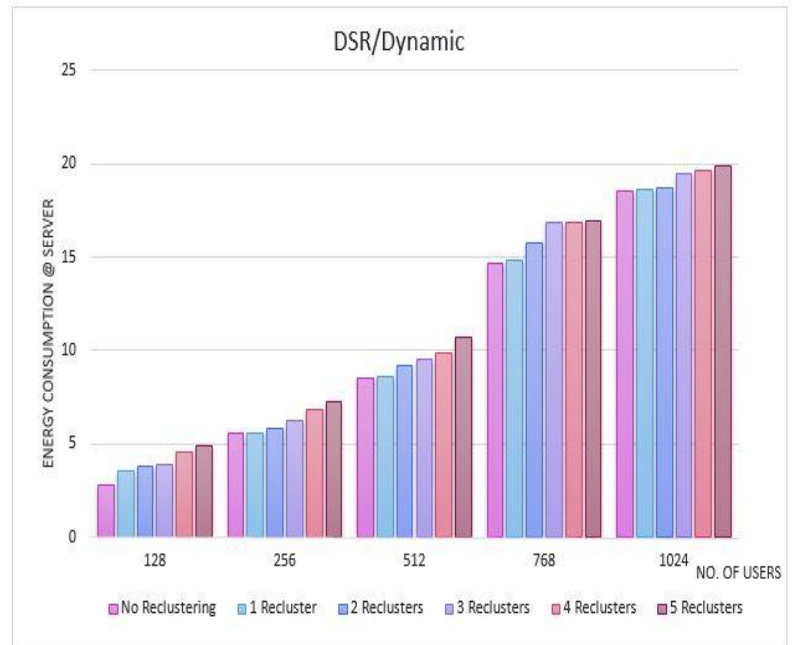

Figure 10: Group Size versus Energy Consumption at Server (Dynamic scenario) for 0 to 5 times Re-clustering

Figure 10 displays Energy Consumption at Server in the network in case of Dynamic category for 0 to 5 times Reclustering in Dynamic Source Routing Protocol. Energy Consumption at Server in the Dynamic category is more as compared to the Static category and Semi-Dynamic category. 


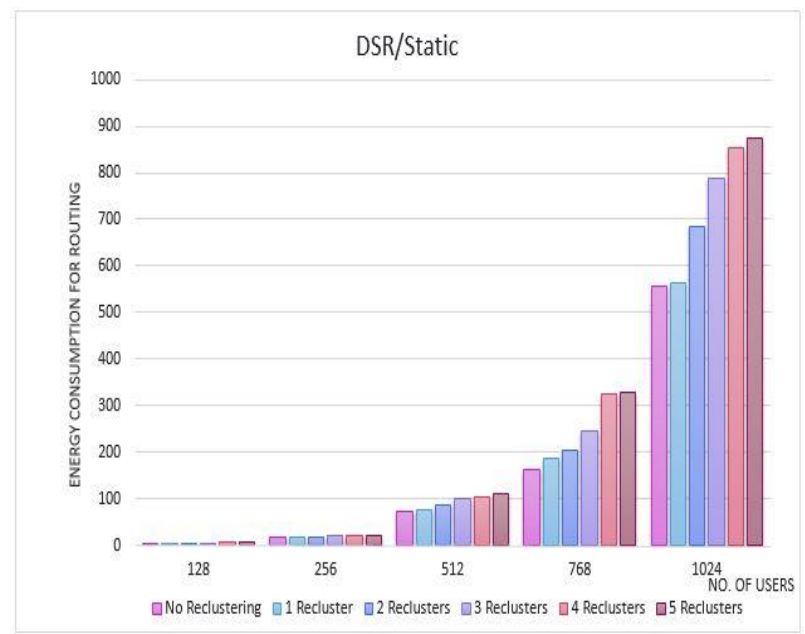

Figure 11: Group Size versus Energy Consumption for Routing (Static scenario) for 0 to 5 times Re-clustering

Figure 11 displays Energy Consumption for Routing in the network in case of Static category for 0 to 5 times Reclustering in Dynamic Source Routing Protocol. Energy Consumption for Routing in the Static category is less as compared to the Semi-Dynamic category and Dynamic category.

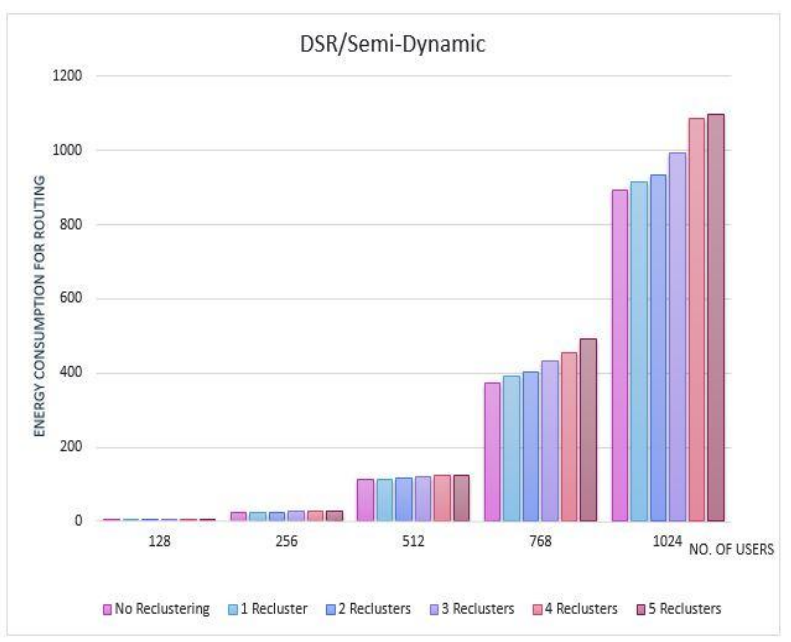

Figure 12: Group Size versus Energy Consumption for Routing (Semi-Dynamic scenario) for 0 to 5 times Reclustering

Figure 12 displays Energy Consumption for Routing in the network in case of Semi-Dynamic category for 0 to 5 times Re-clustering in Dynamic Source Routing Protocol. Energy Consumption for Routing in the Semi-Dynamic category is less as compared to the Dynamic category.

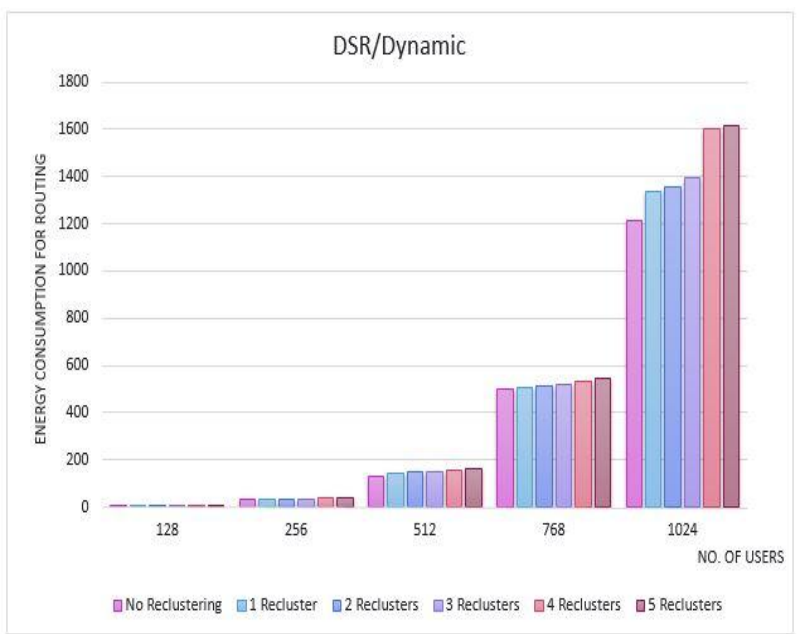

Figure 13: Group Size versus Energy Consumption for Routing (Dynamic scenario) for 0 to 5 times Re-clustering

Figure 13 displays Energy consumption for Routing in the network in case of Dynamic category for 0 to 5 times Reclustering in Dynamic Source Routing Protocol. Energy Consumption for Routing in the Dynamic category is more as compared to the Static category and Semi-Dynamic category.

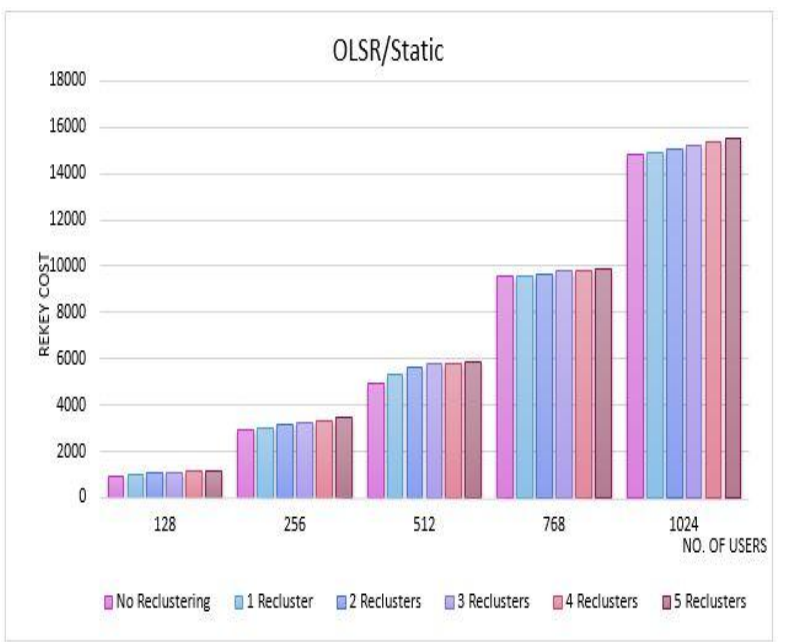

Figure 14: Group Size versus Rekey Cost (Static Scenario) for 0 to 5 times Re-clustering

Figure 14 displays Rekey Cost in the network in case of Static category for 0 to 5 times Re-clustering in Optimal Link State Routing Protocol. Rekey Cost in the Static category is less as compared to the Semi-Dynamic category and Dynamic category. Here, it is observed that if the number of Reclustering increases, the Rekey Cost also increases. 


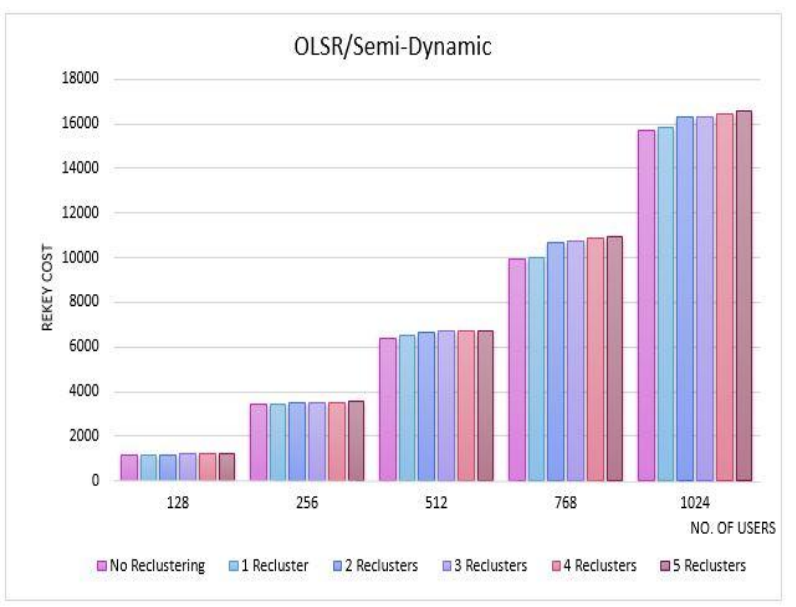

Figure 15: Group Size versus Rekey Cost (Semi-Dynamic Scenario) for 0 to 5 times Re-clustering

Figure 15 displays Rekey Cost in the network in case of Semi-Dynamic category for 0 to 5 times Re-clustering in Optimal Link State Routing Protocol. Rekey Cost in the SemiDynamic category is less as compared to the Dynamic category. Here, it is observed that if the number of Reclustering increases, the Rekey Cost also increases.

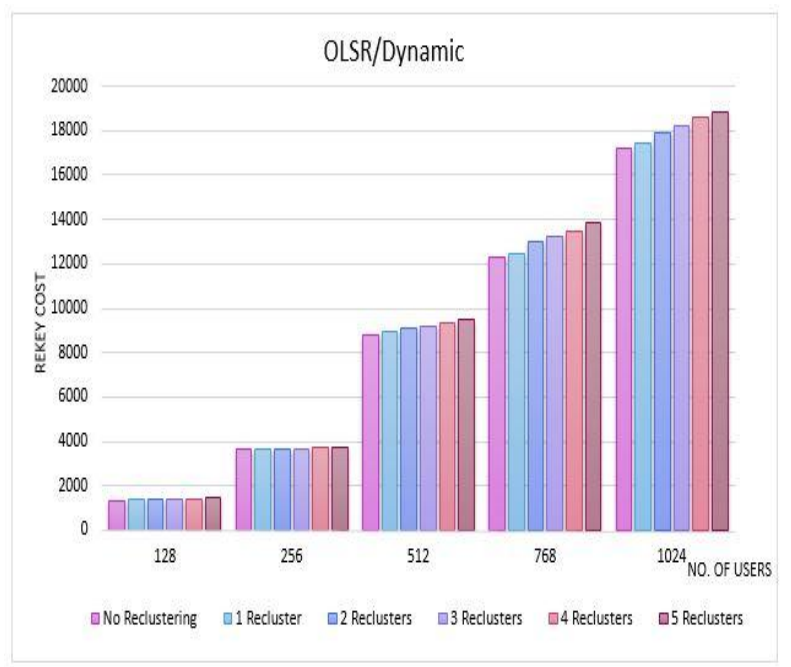

Figure 16: Group Size versus Rekey Cost (Dynamic Scenario) for 0 to 5 times Re-clustering

Figure 16 displays Rekey Cost in the network in case of Dynamic category for 0 to 5 times Re-clustering in Optimal Link State Routing Protocol. Rekey Cost in the Dynamic category is more as compared to the Static category and SemiDynamic category. Here, it is observed that if the number of Re-clustering increases, the Rekey Cost also increases.

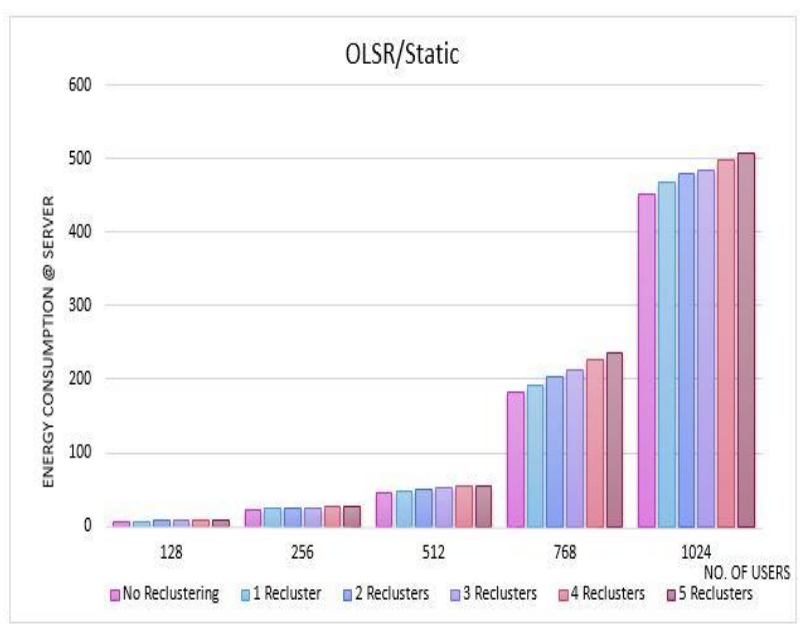

Figure 17: Group Size versus Energy Consumption at Server (Static scenario) for 0 to 5 times Re-clustering

Figure 17 displays Energy Consumption at Server in the network in case of Static category for 0 to 5 times Reclustering in Optimal Link State Routing Protocol. Energy Consumption at Server in the Static category is less as compared to the Semi-Dynamic category and Dynamic category.

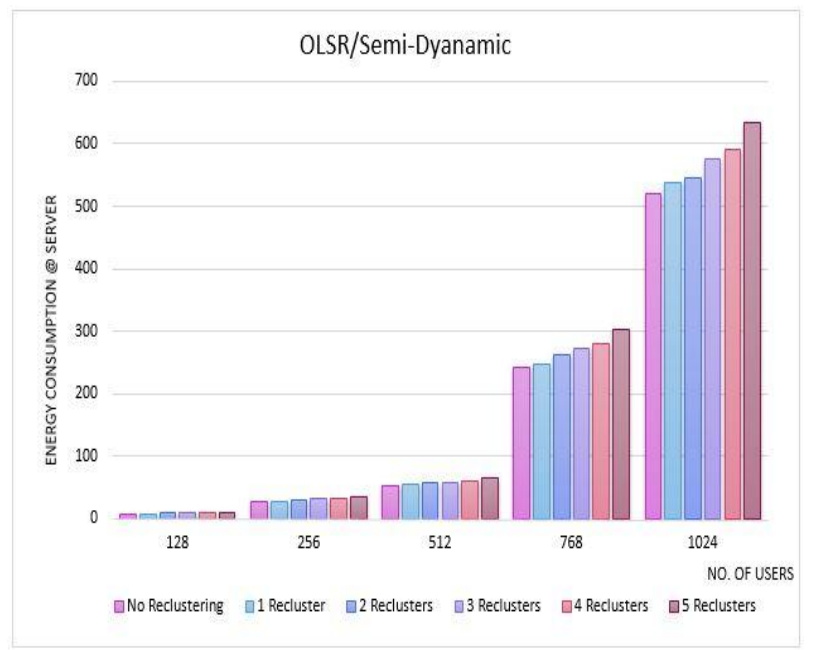

Figure 18: Group Size versus Energy Consumption at Server (Semi-Dynamic scenario) for 0 to 5 times Re-clustering

Figure 18 displays Energy Consumption at Server in the network in case of Semi-Dynamic category for 0 to 5 times Re-clustering in Optimal Link State Routing Protocol. Energy Consumption at Server in the Semi-Dynamic category is less as compared to the Dynamic category. 


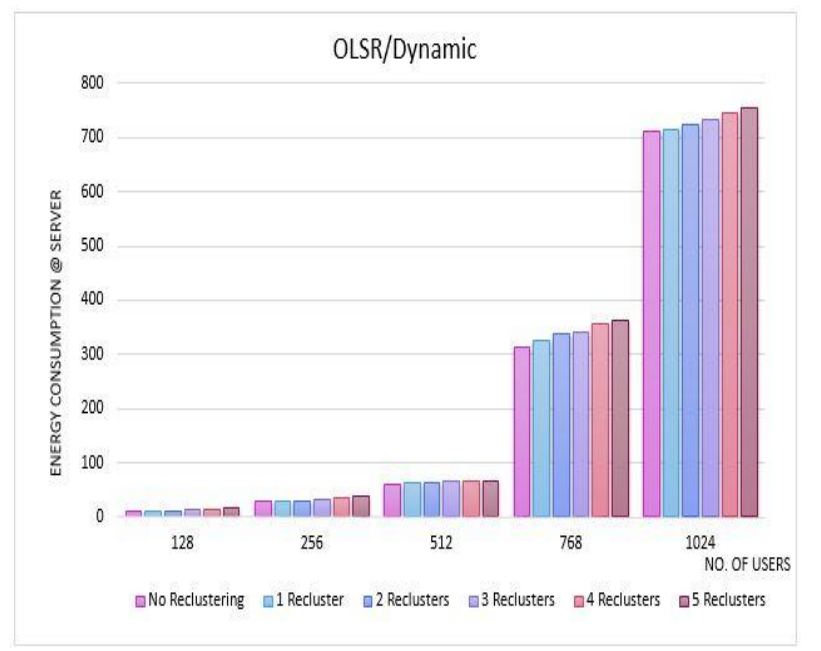

Figure 19: Group Size versus Energy Consumption at Server (Dynamic scenario) for 0 to 5 times Re-clustering

Figure 19 displays Energy Consumption at Server in the network in case of Dynamic category for 0 to 5 times Reclustering in Optimal Link State Routing Protocol. Energy Consumption at Server in the Dynamic category is more as compared to the Static category and Semi-Dynamic category.

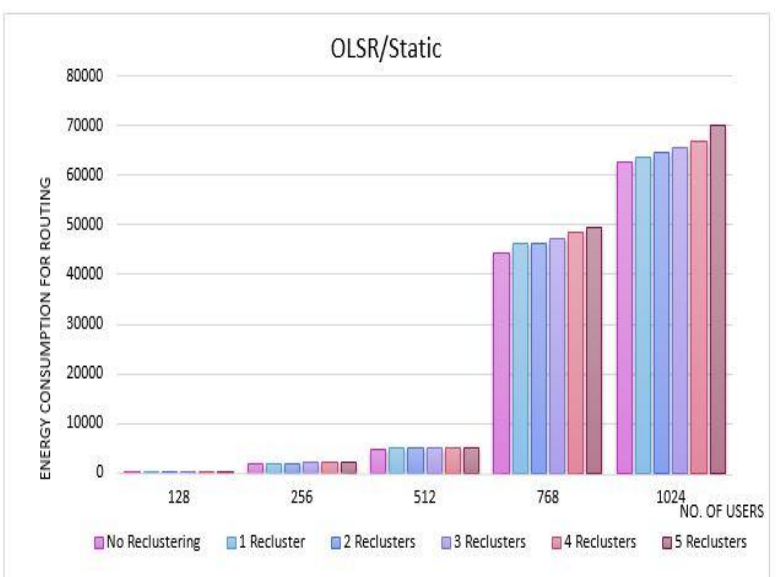

Figure 20: Group Size versus Energy Consumption for

Routing (Static scenario) for 0 to 5 times Re-clustering

Figure 20 displays Energy Consumption for Routing in the network in case of Static category for 0 to 5 times Reclustering in Optimal Link State Routing Protocol. Energy Consumption for Routing in the Static category is less as compared to the Semi-Dynamic category and Dynamic category.

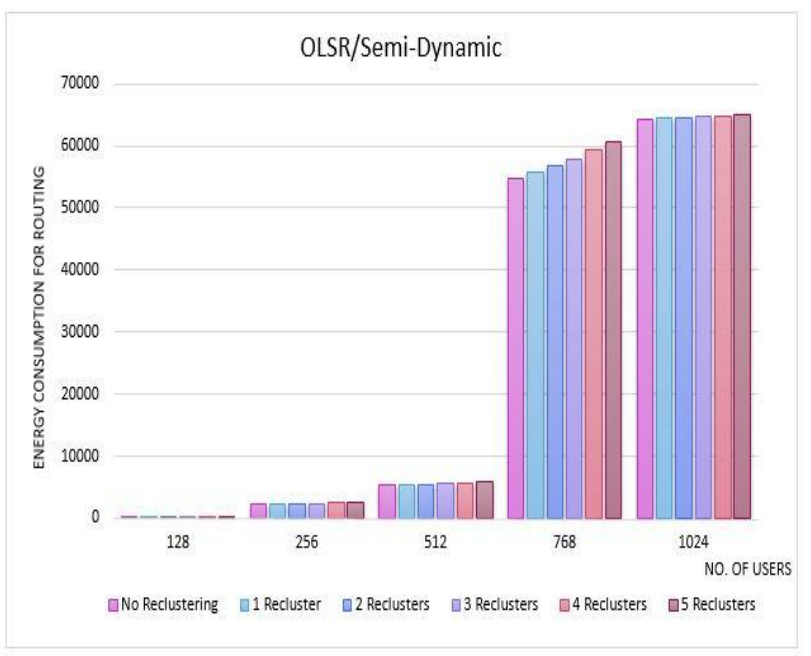

Figure 21: Group Size versus Energy Consumption for Routing (Semi-Dynamic scenario) for 0 to 5 times Reclustering

Figure 21 displays Energy Consumption for Routing in the network in case of Semi-Dynamic category for 0 to 5 times Re-clustering in Optimal Link State Routing Protocol. Energy Consumption for Routing in the Semi-Dynamic category is less as compared to the Dynamic category.

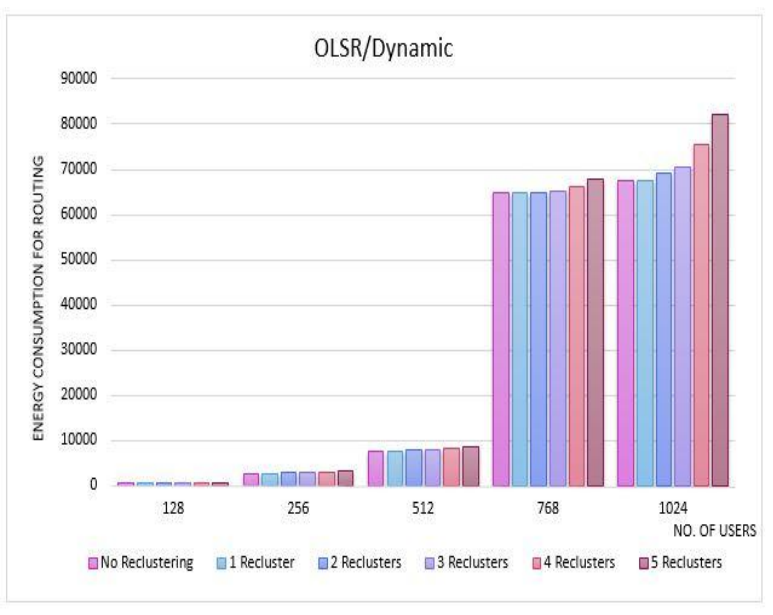

Figure 22: Group Size versus Energy Consumption for Routing (Dynamic scenario) for 0 to 5 times Re-clustering

Figure 22 displays Energy consumption for Routing in the network in case of Dynamic category for 0 to 5 times Reclustering in Optimal Link State Routing Protocol. Energy Consumption for Routing in the Dynamic category is more as compared to the Static category and Semi-Dynamic category.

\section{CONCLUSION}

We suggested an on-demand weighted clustering algorithm (WCA) which can dynamically adapt itself with the ever fluctuating topology of ad-hoc networks. Assigning different weights and taking into an account a combined effect of the ideal degree, mobility, transmission power and battery power of the nodes is the flexibility of the weighted clustering algorithm. The algorithm is implemented only when there is a need, i.e., when a node is no longer capable to attach itself to any of the prevailing clusterheads. Re-clustering arises 
because of change in the key-server. If key-server changes, the new key-server needs to generate and distribute the new keys to all the members in the group. In this section, we present the Rekey Cost and energy consumption values for 0 to 5 times Re-clustering in Static,Semi-Dynamic and Dynamic scenarios. As the number of Re-clustering increases, the Rekey Cost and other energy consumptions also increases.

\section{REFERENCES}

[1] Koey Huishan, Chua Huimin and Koh Yeow Nam, "Routing Protocols in Ad-hoc Wireless Networks", National University of Singapore.

[2] T. Clausen and P. Jacquet, "Optimized Link State Routing Protocol (OLSR)", RFC 3626, IETF Network Working Group, October 2003.

[3] Sapna S. Kaushik and P.R. Deshmukh, Comparison of Effectiveness of AODV, DSDV and DSR Routing Protocols in Mobile AD-hoc Networks.

[4] http://www.digplanet.com/wiki/Random_waypoint_model.

[5] Nachiketh R. Potlapally, Srivaths Ravi, Anand Raghunathan and Niraj K. Jha, "Analyzing the Energy Consumption of Security Protocols", in Proc. ISLPED’03, ACM 1-58113-682-X/03/0008.

[6] K.Gomathi and B.Parvathavarthini, "An Efficient Cluster based Key Management Scheme for MANET with Authentication", Trendz in Information Sciences \& Computing (TISC), 2010.

[7] S. Basagni, "Distributed Clustering for Ad-hoc Networks",International Symposiun on Parallel Architectures, Algorithms and Networks, Perth, Pp. 310-315, 1999,.

[8] Mainak Chatterjee, Sajal K. Das and Damla Turgut, "An On-demand Weighted Clustering Algorithm (WCA) for Ad-hoc Networks", IEEE, 2000 . 